\title{
Performance of a sacrificial cladding structure made of empty recyclable metal beverage cans under large-scale air blast load
}

\author{
Sivakumar Palanivelu ${ }^{1, a}$, Wim Van Paepegem ${ }^{1}$, Joris Degrieck ${ }^{1}$, \\ Bruno Reymen $^{2, b}$, Eric Segers ${ }^{2}$, Jean-Marie Ndambi ${ }^{2}$, John Vantomme ${ }^{2}$, \\ Johan Van Ackeren ${ }^{3, c}$, Jan Wastiels ${ }^{3}$, Dimitrios Kakogiannis ${ }^{3}$, \\ Danny Van Hemelrijck ${ }^{3}$
}

\author{
${ }^{1}$ Department of Materials Science and Engineering, Ghent University, Sint-Pietersnieuwstraat 41, \\ 9000 Gent, Belgium \\ ${ }^{2}$ Royal Military Academy, Civil and Materials Engineering Department, Building G, Level 0, 8 Av. \\ Hobbema B-1000, Brussels, Belgium \\ ${ }^{3}$ Department of Mechanics of Materials and Construction, Vrije Universiteit Brussel, Pleinlaan 2 B- \\ 1050 Brussels, Belgium \\ a'Sivakumar.Palanivelu@UGent.be; ${ }^{b}$ Bruno.Reymen@rma.ac.be; 'Johan.VanAckren@vub.ac.be
}

Keywords: Empty metal beverage can; Air blast; Reflected pressure; Asymmetric deformation; Peak crush load;

Abstract. This paper demonstrates the use of recyclable waste products such as typical empty metal beverage cans available in the market for the protection of civil engineering structures from an explosive load. The sacrificial cladding structure was made of empty recyclable beverage cans and sandwich composite skin plates. To measure the protection efficiency of these structures large-scale air blast experiments have been conducted. To create a perfect plane shock wave the concept of shock tube was used using concrete sewage pipes. The experimental and numerical crushing performance of the empty beverage cans is studied in detail. Finally, this study concludes that the waste empty metal cans can be considered as a potential member to protect civil engineering structures from the air blast load.

\section{Introduction}

Protecting the civilian population against blast attacks is a complex and comprehensive task. If critical civil structures (tower buildings, embassies etc.,) are threatened, the main concerns are with the elaboration of an efficient rescue plan and a rapid intervention. The structural integrity of the engineering structure itself is rarely considered. However, since the early nineties (bomb attacks World Trade Centre (1993), Oklahoma (1995), US embassy Kenya (1998), World Trade Centre (2001)) the protection of civil engineering structures against explosions has become an important research area. Efforts have been made around the globe to propose suitable solutions for this problem. Out of many proposed solutions, the concept of sacrificial cladding design [1, 2] has attracted more attention in terms of its functionality and its predictable behaviour. Any sacrificial cladding structure can have two layers (an outer skin and an inner core). The function of the outer skin is to distribute the blast pressure more evenly to the inner core which deforms progressively so that the peak force transferred to the non-sacrificial structure can be minimized. In order to safeguard the main load bearing members of the civil engineering structures, the failure load of the sacrificial cladding structure should be kept as low as possible. Keeping a lower failure load for the inner core may attribute to achieve the plastic deformation during an explosion event and so the transferred peak force to the non-sacrificial structure can be minimised. Therefore, in this work, we propose empty recyclable metal beverage cans for the inner core members of the sacrificial cladding structure. The concept of the proposed sacrificial cladding structure using empty recyclable metal beverage cans is shown in Fig. 1. This configuration can be used to protect typical civil engineering structures from air blast loading. The advantages of this sacrificial structure using empty beverage cans are: (i) environment friendly due to recyclable material (ii) it is a waste product and readily 
available in the market and (iii) non-corrosive due to inner lacquer and outer aesthetic coatings (iv) these cans can be adopted in different configurations of macro foam depending upon the blast loading magnitudes. In order to understand the crushing performance of the beverage cans largescale air blast tests have been conducted with two different configurations and with different charge masses (C4). The deformation patterns and the corresponding crushing efficiency of the beverage cans are studied in detail. Before conducting tests, coupled numerical simulations have been performed using Hydrocodes to calculate the reflected parameters. The results from the numerical simulation and the experimental results are compared.

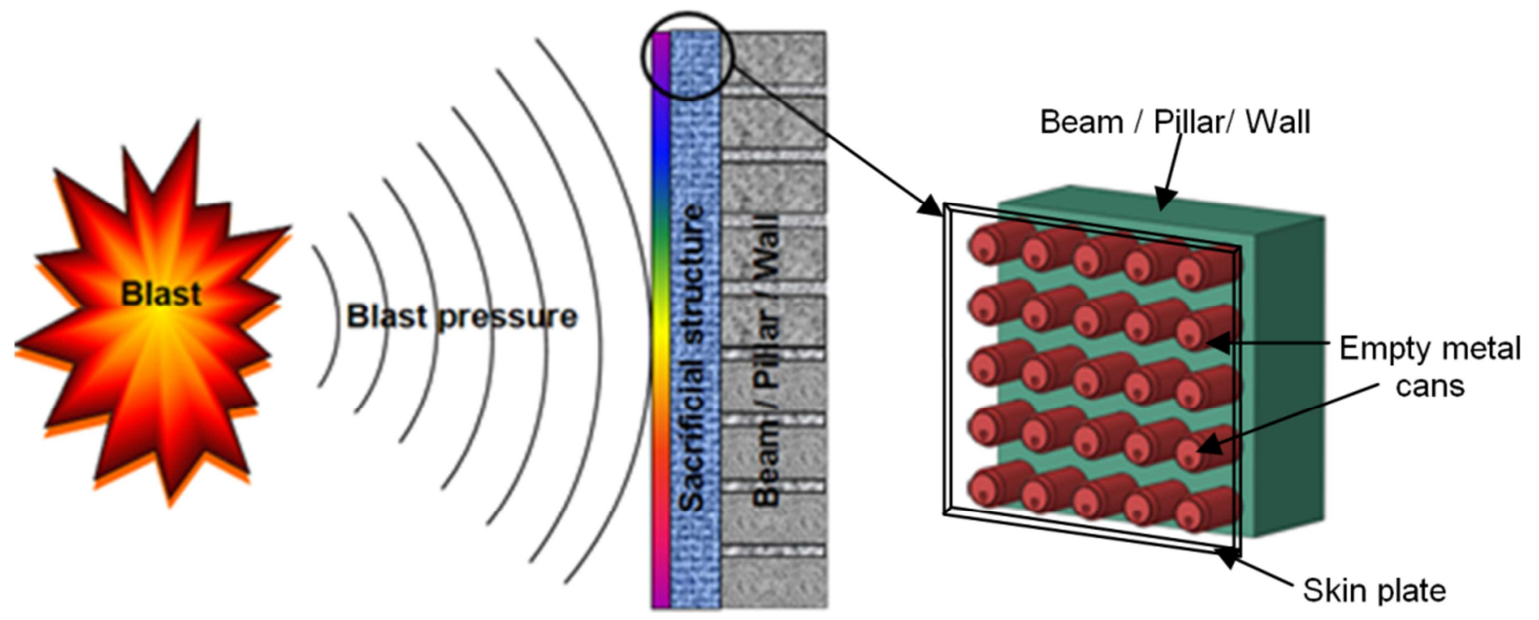

Fig. 1: Concept of proposed sacrificial cladding structure with empty recyclable metal beverage cans.

\section{Test specimen and experimental test set-up}

Used empty recyclable metal beverage cans were selected for this experimental study. Special care was taken to choose cans without defects such as indents and scratches. The metal beverage cans available in the European market can be classified into two types based on the type of material they are made of. Type A is made of a combination of two materials; the entire body is made of steel and the top cover is made of aluminium (Fig. 2(a)). Type B is completely made of aluminium. Due to the larger availability especially in Belgium, Type A was chosen for our experimental study. The measured average mass of a beverage can for this study was $26 \mathrm{~g}$. The details of the geometry of an empty metal beverage can are also shown in Fig. 2(b).

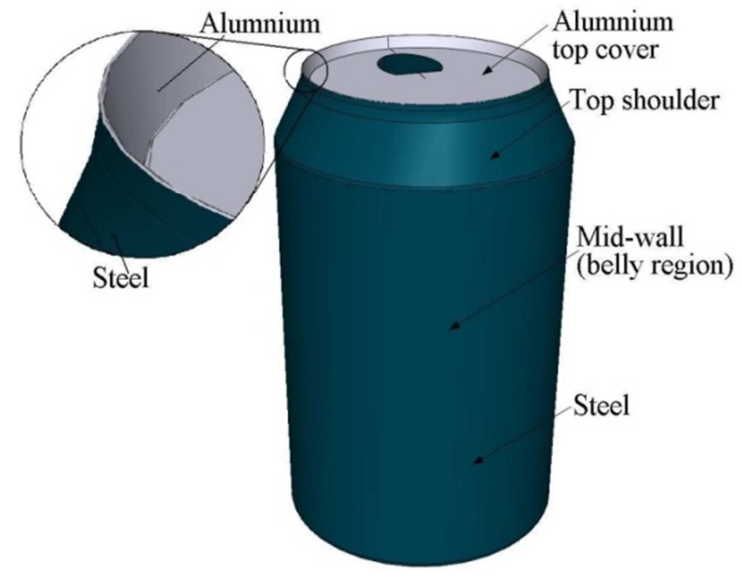

(a) Nomenclature and material details

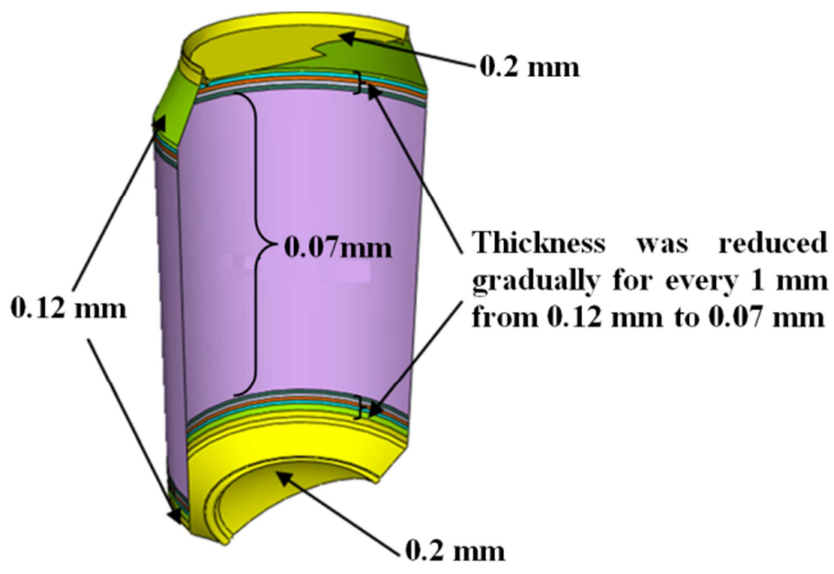

(b) Geometry details

Fig. 2: Material and geometry details of an empty metal beverage can. 
The global view of the experimental test set-up is shown in Fig. 3. The empty metal beverage cans were mounted on a (rear) sandwich composite skin plate behind which three dynamic force sensors were connected to a concrete wall to measure the transferred impulse to the concrete structure. All the skin plates used for the large-scale blast tests were manufactured by $\mathrm{M} / \mathrm{s}$ Acrosoma, Belgium [3]. The sandwich composite skin plates were made of three materials (refer Fig. 4(a)). The outer face sheets (top and bottom) are made of bi-axially balanced glass fibre with polyester resin; the core structure made of divinycell $\mathrm{P}$ foam. The outer face sheets are sewn together straight through the foam with aramid fibres. This prevents the delamination between the face sheets and the core structure (refer Fig. 4(a)). The locations of the force sensors are equidistant from the centre and the angle between these sensors is $120^{\circ}$. Another skin plate was assembled on the front side of the empty beverage cans (test specimens). The diameter of both front and rear skin plates was $1 \mathrm{~m}$ (refer Fig 4(b)). The front skin panel was instrumented with three pressure sensors and two accelerometers to measure the reflected pressure and the acceleration of the skin plate respectively (refer Fig. 3 and 4(b)). The crushing face of the front sandwich skin panel was in-line with the end of the concrete tube which was close to the concrete wall. The $\mathrm{C} 4$ charge was placed at the other end of the concrete pipe (stand-off distance was $4.2 \mathrm{~m}$ - refer Fig. 3). Blast experiments have been conducted on two configurations of the beverage cans ( 25 and 37 beverage cans) with different charge masses $(75 \mathrm{~g}, 100 \mathrm{~g}$ and $150 \mathrm{~g}$ of $\mathrm{C} 4)$. Two high speed cameras were used to capture the crushing behaviour of the beverage cans during the blast loading.

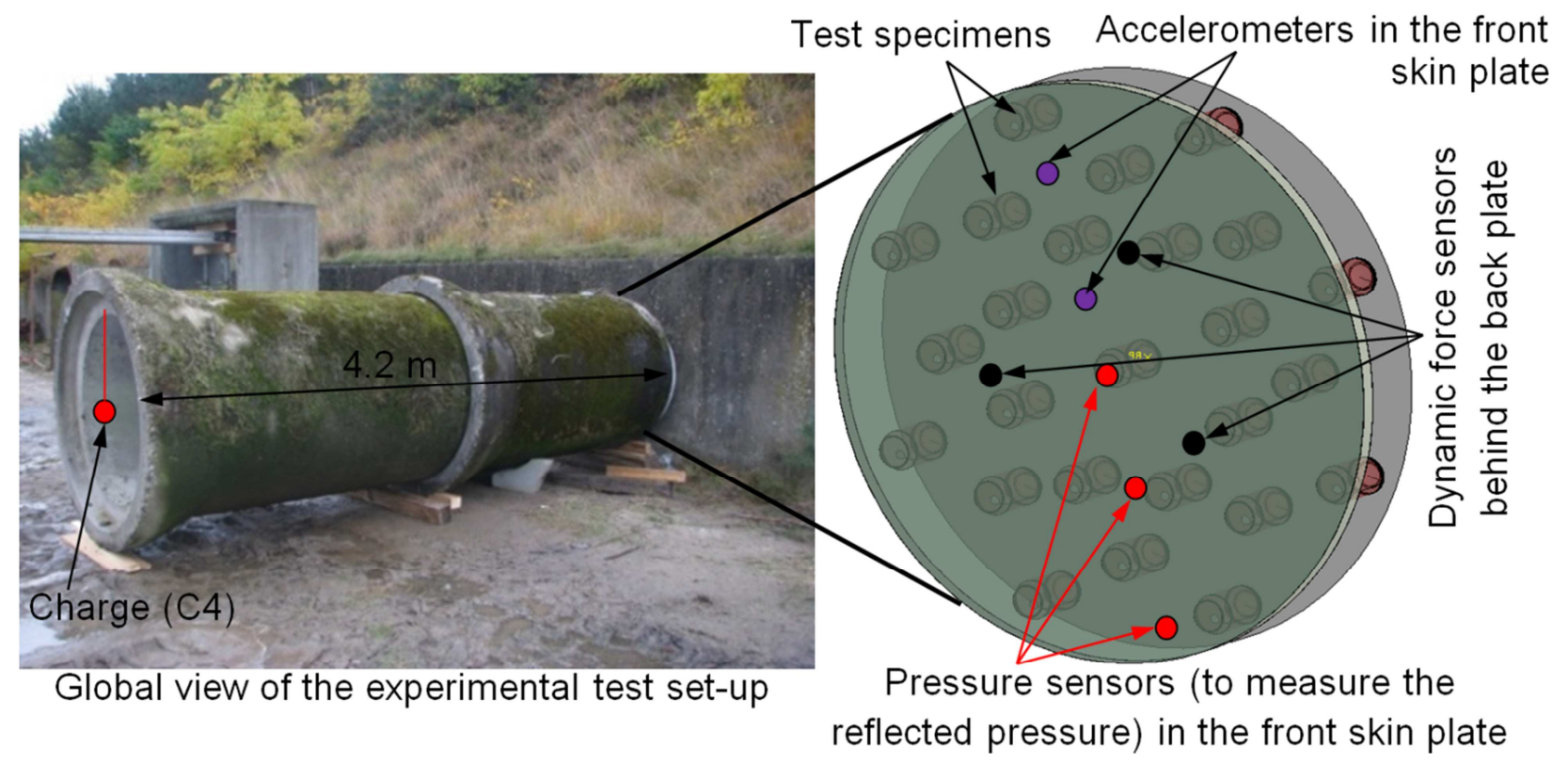

Fig. 3: Schematic representation of the experimental set-up.

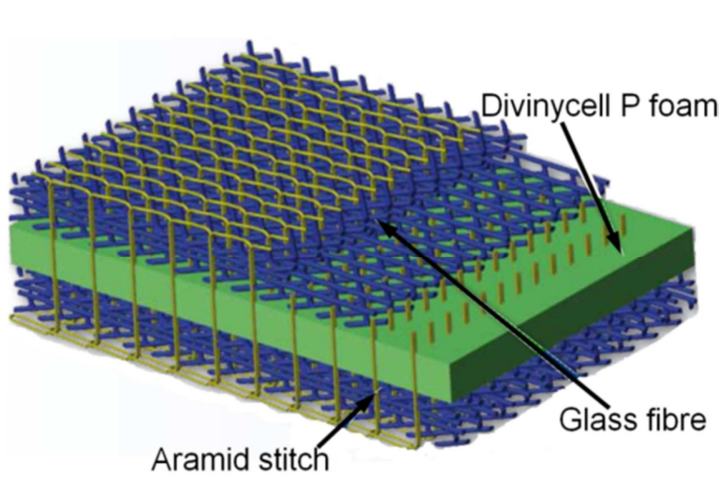

(a) Internal architecture [3]

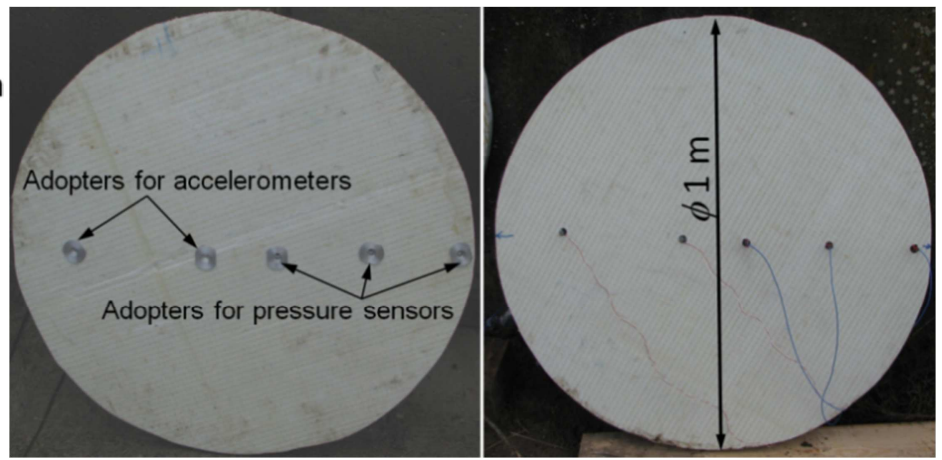

(b) Front sandwich composite skin plates

Fig. 4: Details of front sandwich composite skin panels. 


\section{Results and discussion}

Simulations have been conducted for different charge masses and with different lengths of concrete sewage pipes to identify the length which was required to have a perfectly plane shock wave. The commercially available code Autodyn v12.1 was used. As an example, the simulated propagation of the pressure wave inside the concrete sewage pipes for $150 \mathrm{~g} \mathrm{C} 4$ with $4.2 \mathrm{~m}$ stand-off distance is discussed here. The air and $\mathrm{C} 4$ were modelled using multi-material Euler formulation. The initiation, detonation and the expansion of $\mathrm{C} 4$ was modelled using the Jones-Wilkins-Lee (JWL) Equation of state (EOS) which can be written as

$$
p=C_{1}\left(1-\frac{\omega}{r_{1} v}\right) \exp ^{-r_{1} v}+C_{2}\left(1-\frac{\omega}{r_{2} v}\right) \exp ^{-r_{2} v}+\frac{\omega e}{v}
$$

where $p$ is the hydrostatic pressure $(\mathrm{Pa}), \rho$ is the density $\left(\mathrm{kg} / \mathrm{m}^{3}\right) ; v=1 / \rho$ is the specific volume $\left(\mathrm{m}^{3} / \mathrm{kg}\right) ; e$ is the specific internal energy $(\mathrm{J})$; and $C_{1}, C_{2}, r_{1}, r_{2}$ and $\omega$ are adiabatic constants (these constants can be determined from dynamic experiments and values are available for most commonly used explosives such as $\mathrm{C} 4$ ). The adopted values of the constants of $\mathrm{C} 4$ are $C_{1}=$ $6.097699 \times 10^{8} \mathrm{kPa} ; C_{2}=1.2950 \times 10^{7} \mathrm{kPa} ; r_{1}=4.5 ; r_{2}=1.4$ and $\omega=0.25$ [4]. For large expansion ratios of the explosive, the first and second term of Equation 1 become negligible [5] and the behaviour of the explosive can be considered as an ideal gas. Hence, similar to the approach handled in [5] when the volume of the explosive has expanded by a factor 10, the EOS of the explosive (JWL equation) changes into the EOS of an ideal gas which can be written as

$$
p=(\gamma-1) \rho e
$$

The standard properties of air $\left(\rho=1.225 \mathrm{~kg} / \mathrm{m}^{3}\right.$; adiabatic gas constant $\left.\gamma=1.4\right)$ were used for this simulation. The internal energy of air (e) was assumed to be $2.068 \times 10^{5} \mathrm{~kJ} / \mathrm{kg}$ [4]. Moreover, the adiabatic constant of the explosive, $\omega$, was related to the adiabatic exponent $\gamma$ of an ideal gas by the following relation [5]

$\gamma=\omega+1$

Using the above Equation Of States, the spherical charge of $150 \mathrm{~g} \mathrm{C4}$ was modelled with an equivalent radius of $28.17 \mathrm{~mm}$. Similarly, the volume filled inside the sewage concrete pipe with ambient air was modelled using the ideal gas equation (Equation 2). As an example, one of the cases (150g C4 with $4.2 \mathrm{~m}$ stand-off distance) is presented here. Fig.5 shows the detonation of C4 and the corresponding propagation of the pressure wave inside the sewage concrete pipes. It can be noticed from the same figure that that a perfectly plane shock wave was formed at the other end of the tube.

Fig. 6(a) shows a comparison of the experimentally measured and numerically calculated (Autodyn simulation) reflected pressure-time histories. It can be noticed that there was a good correlation for peak reflected pressure and the positive duration of the blast.

For all tests the empty beverage cans crushed progressively during the explosive loading (refer Fig. 6(b)). The crushed beverage cans showed an asymmetric failure pattern (diamond failure mode). The occurrence of the diamond mode deformation depends upon the combined effect of $D / t$ ratio ( $\sim 937$ for beverage can) and material strain hardening characteristics [6]. As an example, the final deformation pattern of one of the beverage cans is shown in Fig. 7(a). The corresponding transferred load to the concrete structure from one of the load cells is shown in Fig. 7(b). In order to compare the effectiveness of the proposed sacrificial cladding structure, a blast test was conducted only on sandwich composite panels without any beverage cans. The charge and the stand-off distance for this test are the same as for the previous tests (150g of C4 with $4.2 \mathrm{~m}$ stand-off). Two 
sandwich panels (front and rear) were placed next to each other. The results from this experiment showed no significant deformation of the sandwich composite skin panels; and the corresponding transferred load to the concrete structure is shown in Fig. 7(b). It can be noticed from the same figure that the use of the beverage cans reduced the peak crush load significantly; furthermore, the total duration of the event was extended considerably (refer Fig. 7(b)).

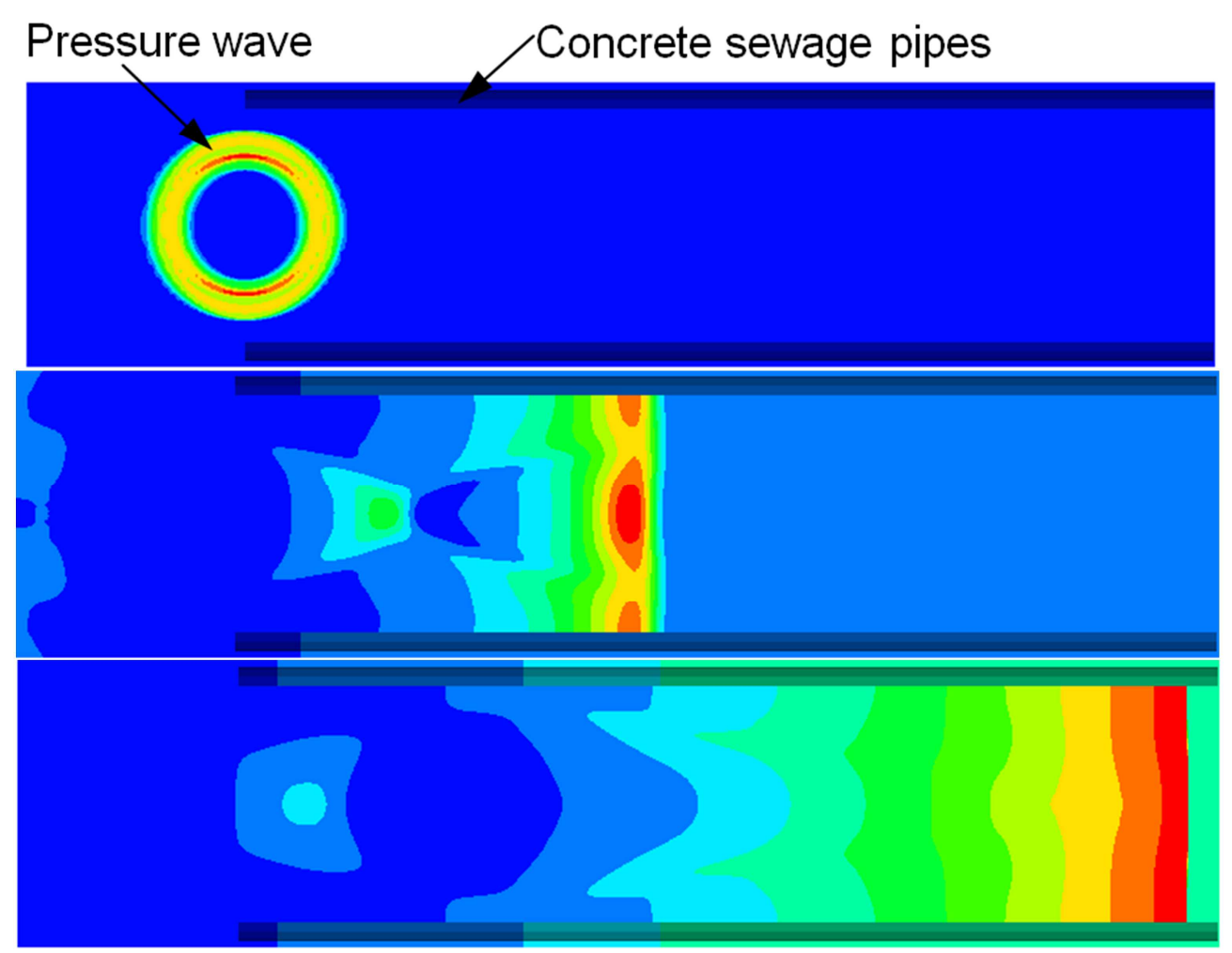

Fig. 5: Propagation of blast pressure wave inside the concrete sewage pipes.

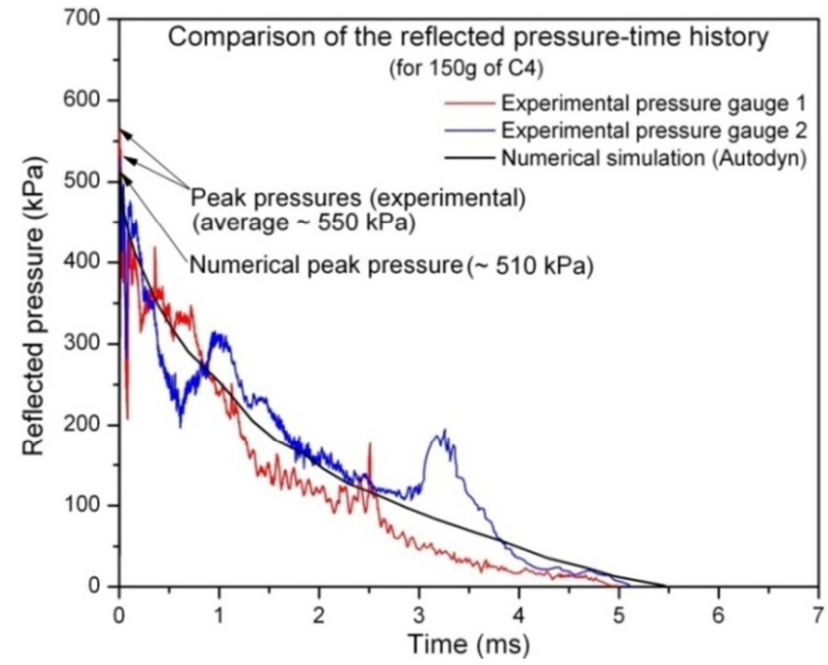

(a)
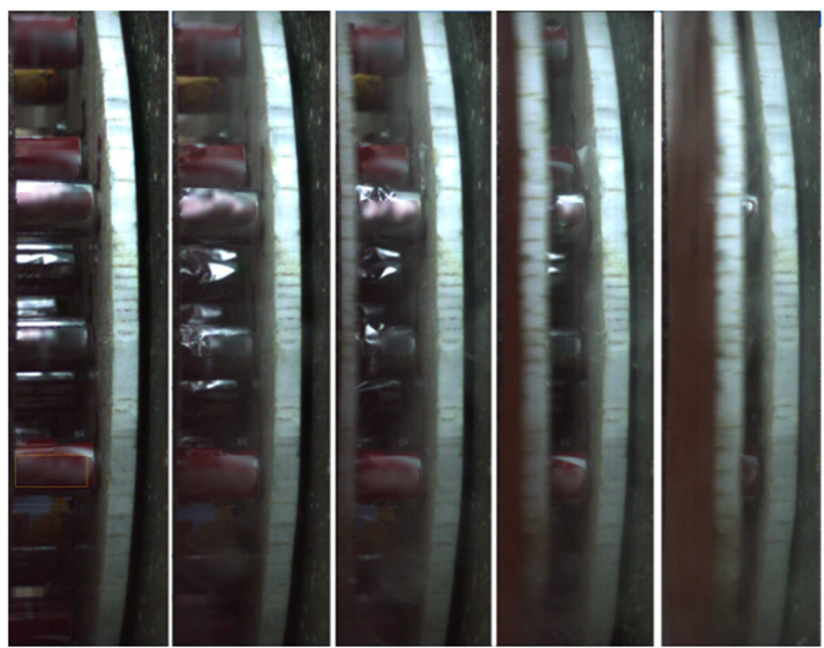

(b)

Fig. 6: (a) Comparison of the reflected pressure-time histories. (b) Progressive crushing stages of beverage cans. 


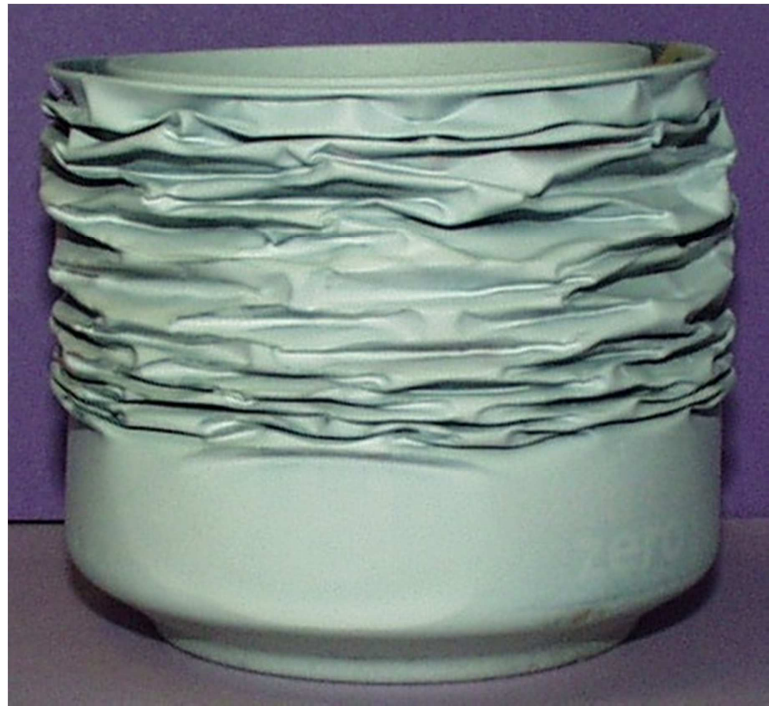

(a)

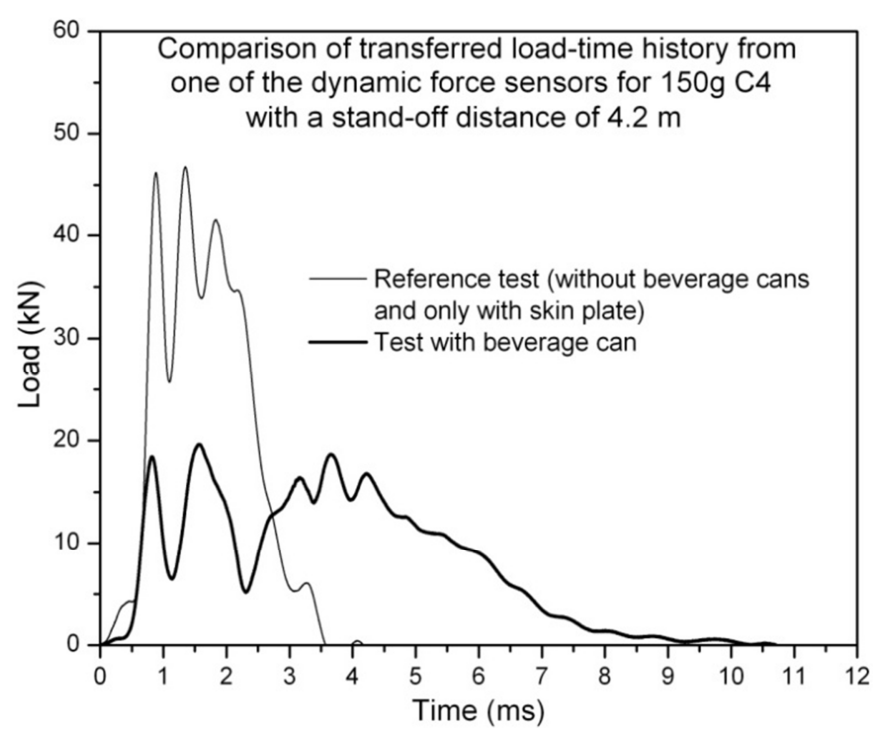

(b)

Fig. 7: (a) Example of final deformation pattern of a beverage can. (b) Comparison of transferred load-time histories.

\section{Conclusions}

To understand the blast mitigation performance of the proposed sacrificial cladding structure using empty metal beverage cans, large-scale air blast experiments have been conducted. The concrete sewage pipes have been successfully employed to create a perfectly plane shock wave. The charge masses and the stand-off distances were decided based on coupled numerical simulations. The results from the numerical simulation showed a good correlation with the experimental data. For all tests, the empty beverage cans showed a progressive asymmetric (diamond mode) deformation pattern. Furthermore, the use of empty beverage cans reduced the peak load which was transferred to the non-sacrificial structure (concrete wall) and extended the crushing time significantly. From the above results, it can be concluded that the empty metal beverage cans can be considered as a potential member to protect civil engineering structures from air blast load.

\section{Acknowledgements}

The authors gratefully acknowledge the financial support of the "Fund for Scientific Research" Flanders (F.W.O) (Grant No: G.0114.07).

\section{References}

[1] S. Guruprasad and Abhijit Mukherjee, Layered sacrificial claddings under blast loading Part II - experimental studies. International Journal of Impact Engineering, 2000. 24(9): p. 975-984.

[2] A. G. Hanssen, L. Enstock and M. Langseth, Close-range blast loading of aluminium foam panels. International Journal of Impact Engineering, 2002. 27(6): p. 593-618.

[3] www.acrosoma.com.

[4] Autodyn, Theory manual. M/s Century Dynamics, 2007.

[5] B. Luccioni, D. Ambrosini and R. Danesi, Blast load assessment using hydrocodes. Engineering Structures, 2006. 28(12): p. 1736-1744.

[6] A. A. Singace, Axial crushing analysis of tubes deforming in the multi-lobe mode. International Journal of Mechanical Sciences, 1999. 41(7): p. 865-890. 
Performance, Protection and Strengthening of Structures under Extreme Loading doi:10.4028/www.scientific.net/AMM.82

Performance of Sacrificial Cladding Structure Made of Empty Recyclable Metal Beverage Cans under Large-Scale Air Blast Load

doi:10.4028/www.scientific.net/AMM.82.416 